\title{
Folate Receptor-Targeted Theranostic Nanoconstruct for Surface- Enhanced Raman Scattering Imaging and Photodynamic Therapy
}

\author{
Andrew M. Fales, ${ }^{\dagger, \downarrow, \perp, \|}$ Bridget M. Crawford, ${ }^{\dagger, \downarrow, \perp}$ and Tuan Vo-Dinh ${ }^{* \dagger, t, \delta}$
}

${ }^{\dagger}$ Fitzpatrick Institute for Photonics, ${ }^{\ddagger}$ Department of Biomedical Engineering, and ${ }^{\S}$ Department of Chemistry, Duke University, 101 Science Drive, Box 90281, Durham, North Carolina 27708, United States

\section{Supporting Information}

ABSTRACT: We report the synthesis of a folate receptor (FR)-targeted theranostic nanocomposite for surface-enhanced Raman scattering (SERS) imaging and photodynamic therapy (PDT). FR-specific SERS detection and PDT are demonstrated in vitro using two FR-positive cancer cell lines and one FR-negative cancer cell lines.

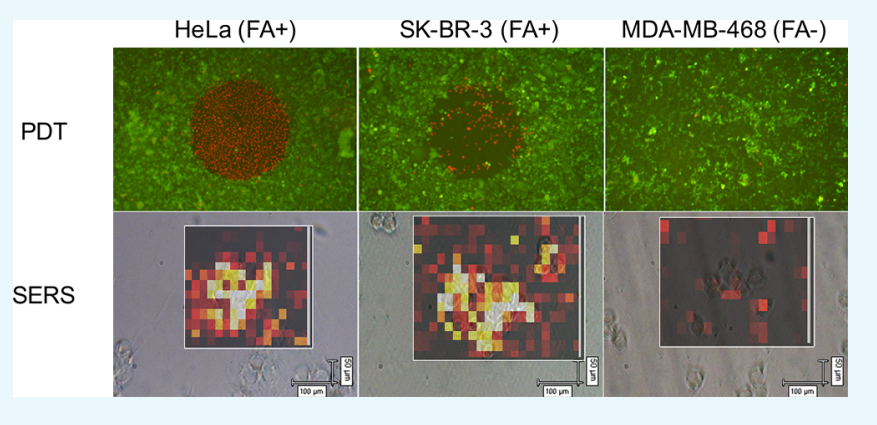

\section{INTRODUCTION}

Theranostics, the seamless combination of therapy and diagnostics into a single construct, has become an active area of research in the field of nanomedicine. ${ }^{1,2}$ This combination offers to provide more personalized treatment, specific to the molecular phenotype of the disease, to improve patient outcomes, and to reduce off-target effects. ${ }^{3}$ Recent advances in nanotechnology and the unique properties of nanoparticles make them ideal for the use as theranostic agents, combining an imaging modality with a therapeutic function. ${ }^{1,4}$ Plasmonic nanoparticles are one class of nanoparticles that have been used extensively in imaging applications.

The strong electromagnetic field enhancement produced by plasmonic particles under appropriate excitation light can be used for surface-enhanced Raman scattering (SERS), a very sensitive and specific spectroscopic technique. ${ }^{6,7}$ Recent advances in the synthesis and modification of nanoparticles have brought about the use of Raman dye-labeled nanoparticles as contrast agents in in vitro, ex vivo, and in vivo studies. ${ }^{8-10}$ It has been shown that SERS tags can be as bright as fluorescent tags, while not suffering from photobleaching effects. ${ }^{11}$ SERS tags are also more suitable for multiplex detection, exhibiting sharp, fingerprint-like spectra, in contrast to the broad, featureless emission spectra of fluorescent tags. ${ }^{12}$

Photodynamic therapy (PDT) is a promising treatment for a variety of diseases, including cancer. ${ }^{13}$ When a photosensitizer is activated with the appropriate wavelength of light, it can undergo intersystem crossing to an excited triplet state. In the presence of molecular oxygen $\left({ }^{3} \mathrm{O}_{2}\right)$, the photosensitzer in its excited triplet state can transfer its energy, producing singlet oxygen $\left({ }^{1} \mathrm{O}_{2}\right)$ and other cytotoxic reactive oxygen species, destroying cells in the immediate vicinity. ${ }^{14}$ One of the main obstacles to applying PDT clinically is the inactivation or poor solubility of the photosensitizer in biological environments. 15,16
Loading of the photosensitizer onto a nanoparticle can overcome these problems by both protecting the molecule from degradation and acting as a carrier for delivery to the intended target. $^{17}$

To create a true theranostic construct, the ability to detect and treat must be specific to a subtype of cells. Folic acid (FA) is one of the most common targeting ligands employed for the nanoparticle delivery. ${ }^{18}$ Many cancer cells overexpress the folate receptor (FR), whereas normal cells typically have little to no FR expression. By functionalizing the surface of our nanoparticles with FA, they can be used to specifically label FRpositive cells for detection by SERS, followed by PDT.

In this report, we present the synthesis of a FR-targeted theranostic nanoparticle. The diagnostic aspect of the construct comes from a silver-embedded gold nanostar that acts as a SERS tag for Raman imaging. Photosensitizer molecules are loaded onto the SERS tag by encapsulating them in a silica shell for PDT. Selective detection and treatment of the FR-positive cells are demonstrated using HeLa cervical cancer and SK-BR-3 breast cancer cells. ${ }^{19-21}$ MDA-MB-468 breast cancer cells are used as a FR-negative control. ${ }^{19,20}$

\section{RESULTS AND DISCUSSION}

The nanotheranostic agent presented in this study was synthesized by combining different aspects from our previously developed protocols. The gold nanostars were prepared using a modified version of the surfactant-free nanostar procedure that was first reported from our laboratory. ${ }^{22}$ By adding silver nitrate immediately before ascorbic acid (AA), batch-to-batch variability is reduced when compared with simultaneous

Received: August 8, 2016

Accepted: October 20, 2016

Published: October 31, 2016 


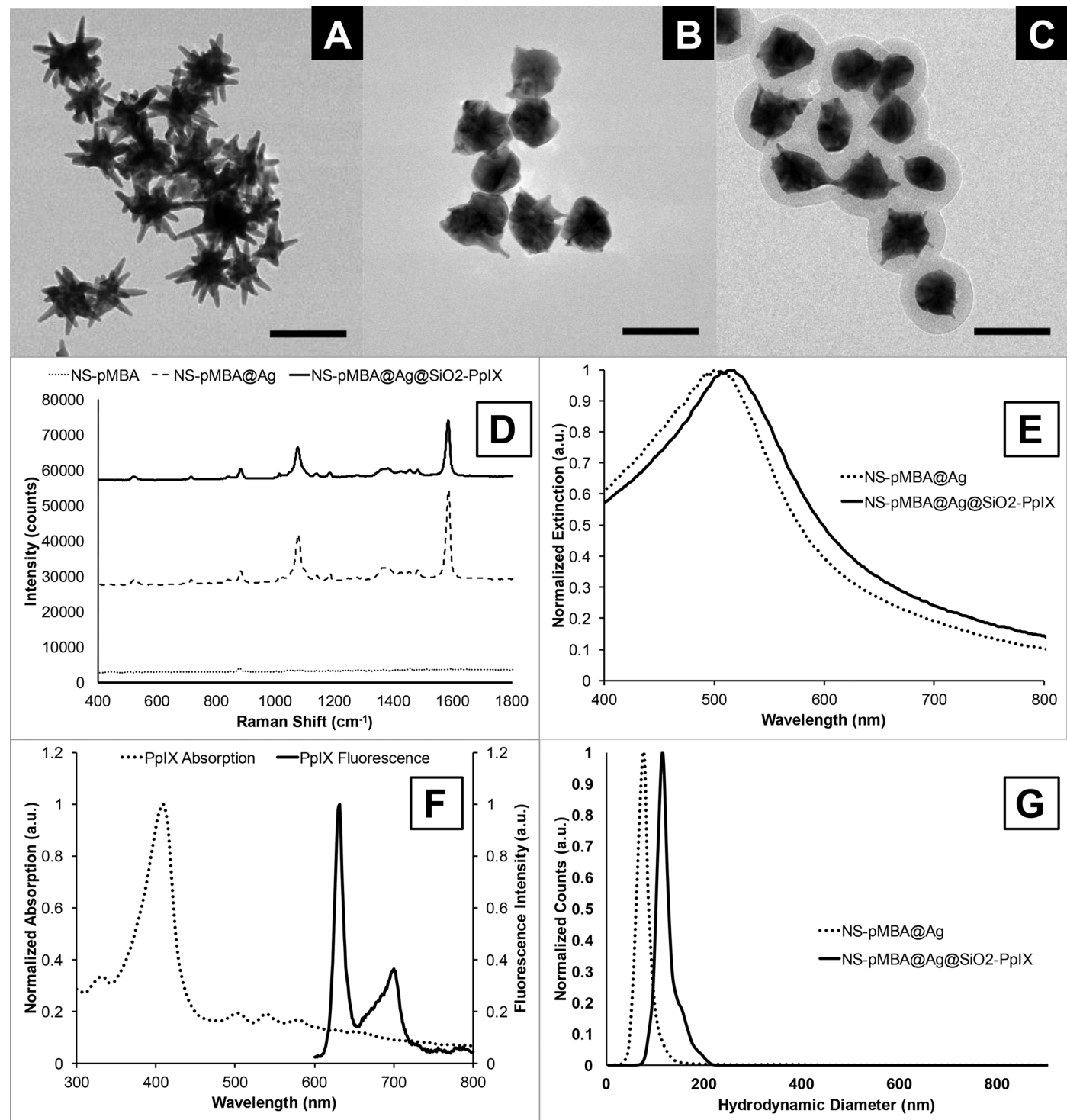

Figure 1. TEM images of gold nanostars (A), $p$ MBA-embedded silver-coated gold nanostars (B), and silica-coated, $p$ MBA-embedded silver-coated gold nanostars (C; scale bars are $100 \mathrm{~nm}$ ). (D) SERS signal from $p$ MBA-labeled gold nanostars (dotted), the silver-embedded $p$ MBA-labeled gold nanostars (dashed), and the silica-coated silver-embedded $p$ MBA-labeled gold nanostars (solid); $10 \mathrm{~s}$ acquisition, $0.65 \mathrm{~mW}$ laser power. (E) UV/vis extinction spectra of the silver-coated nanostars before (dotted) and after (solid) silica coating. (F) PpIX absorption (dotted) and emission (solid) at $415 \mathrm{~nm}$ excitation. (G) Particle size distribution of the silver-coated gold nanostars before (dotted) and after (solid) silica coating.

addition. Figure $1 \mathrm{~A}$ shows transmission electron microscopy (TEM) images of the gold nanostars that were prepared and subsequently functionalized with para-mercaptobenzoic acid ( $p$ MBA). As shown in our recent report, $p$ MBA-labeled gold nanostars can be coated with silver, embedding $p$ MBA between the gold and silver surfaces and generating high SERS enhancement of the embedded dye. ${ }^{23}$ The silver-embedded gold nanostars are shown in Figure 1B. A silica shell was then coated on the silver-embedded gold nanostars to load the photosensitizer, protoporphyrin IX (PpIX), onto the nanoparticles. $^{24}$ The silica shell also allows for amine modification with (3-aminopropyl)triethoxysilane (APTES), which is easily conjugated to FA-polyethyleneglycol- $N$-hydroxysuccinimide (FA-PEG-NHS) to provide both stability in biological environments and FR-targeting capability. A schematic overview of the nanoparticle synthesis can be found in Scheme 1. A TEM micrograph of the final theranostic construct is shown in Figure 1C.
A representative SERS spectrum of the pMBA-embedded particles is presented in Figure 1D, showing the characteristic 1076 and $1580 \mathrm{~cm}^{-1}$ Raman peaks of $p$ MBA ring breathing and stretching, respectively. ${ }^{25}$ The silver-embedded nanoparticles were also characterized using UV/vis absorption spectroscopy (Figure 1E), before (dotted) and after (solid) silica coating and functionalization. The plasmon peak shifts from 506 to $514 \mathrm{~nm}$ after silica coating, as expected owing to the increase in refractive index around the particles. ${ }^{26}$ The absorption and emission spectra of the photosensitizer PpIX are shown in Figure 1F. The amount of PpIX encapsulated in the silica shell was estimated using the fluorescence intensity of PpIX remaining in the supernatant after silica coating (Figure S1). An estimated $0.33 \pm 0.03 \mu \mathrm{M}$ PpIX (33\% loading efficiency of the initial $1 \mu \mathrm{M}$ ) was loaded onto $0.1 \mathrm{nM}$ of particles, which is in good agreement with our previous report. ${ }^{24}$ The efficiency of the FA conjugation was determined spectrophotometrically (Figure S2). It was found that $0.204 \pm 0.007 \mathrm{mg}$ of the initial 2 
Scheme 1. Schematic Representation of the Nanoconstruct Synthesis $^{a}$

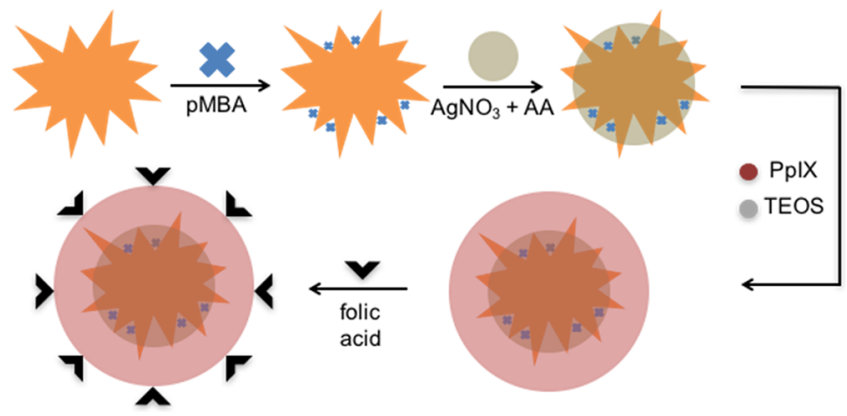

${ }^{a}$ Gold nanostars are first labeled with the Raman dye $p$ MBA. Silver coating is performed by reducing silver nitrate with AA, embedding $p$ MBA between the gold core and silver shell. The photosensitizer, $\mathrm{PpIX}$, is loaded onto the nanoparticles by encapsulation within a silica shell, achieved by adding PpIX during the condensation reaction of the silica precursor, tetraethyl orthosilicate (TEOS). Targeting functionality is realized by the conjugation of FA to the outer surface of the silica shell.

mg FA-PEG-NHS was incorporated onto the particles, providing a conjugation efficiency of about $10 \%$. The particle size distribution was measured using nanoparticle tracking analysis (NTA) (Figure 1G) and found no significant aggregation of particles either before (dotted) or after (solid) silica coating and functionalization.

An in vitro demonstration of SERS-based diagnostics was performed. Two FR-positive cell lines (HeLa and SK-BR-3) and one FR-negative cell line (MDA-MB-468) were used. The cells were incubated with the folate-conjugated nanocomposite for $4 \mathrm{~h}$ in a fresh medium. Following the incubation period, cells were washed three times in phosphate-buffered saline (PBS) before being fixed and dried for imaging. In this case, the cells were fixed because our Raman microscope is not set up to perform live cell measurements. If equipped with a microscope incubator chamber, the SERS detection could be carried out on live samples. The cell sample was placed on the microscope stage, and the cells were located using a $10 \times$ objective. An area for Raman mapping was designated in the microscope software (white boxes in Figure 2). Raman spectra were acquired at each point in a grid across the sample at $20 \mu \mathrm{m}$ step sizes. The intensity of the $1076 \mathrm{~cm}^{-1}$ Raman peak of $p M B A$ was then used to generate the false-color Raman maps by integrating the signal to baseline from 1050 to $1100 \mathrm{~cm}^{-1}$ in the WiRE software. The color scale between all three samples was kept the same. As shown in Figure 2, both HeLa and SK-BR-3 samples show high signal intensity from the FA-targeted nanoparticles, with a low background signal outside of the cellcontaining region. As expected, the MDA-MD-468 samples only show a background level of SERS signal following particle incubation. These results demonstrate the selective detection of FR-positive cells using the developed theranostic construct. To confirm that the high SERS intensity of the FR-positive cells is due to targeting and not due to different rates of nanoparticle uptake between the cell lines, a control experiment with an untargeted theranostic construct was performed (Figure S3). It was observed that none of the cell lines showed a strong SERS signal after the $4 \mathrm{~h}$ incubation period with the untargeted nanoparticles, indicating that there is not a significant rate of nanoparticle uptake by any of the cell lines in the time frame studied.

The cells used for PDT were treated with particles in the same manner as those for SERS detection. Instead of being fixed after PBS washing, a fresh medium was replenished. An area of cells was focused on with a $40 \times$ objective and then exposed to filtered red light $(640 / 30 \mathrm{~nm})$ from a mercury arc lamp for $15 \mathrm{~s}$; the power measured at the sample was $11.5 \mathrm{~mW}$. After irradiation, the cells were returned to the incubator for $4 \mathrm{~h}$

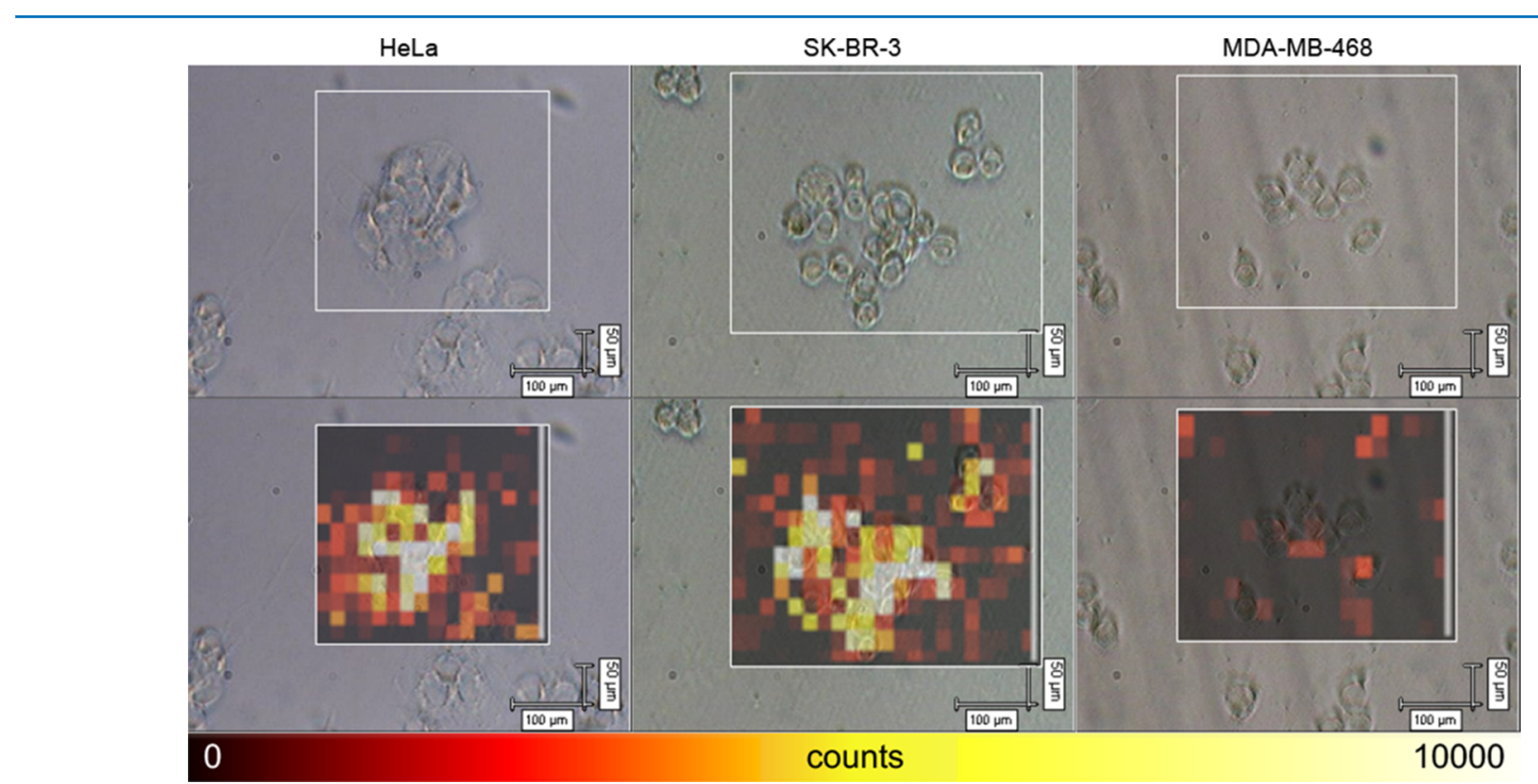

Figure 2. Raman mapping of the three different cell lines after $4 \mathrm{~h}$ incubation with the FA-targeted theranostic nanoparticles at $0.1 \mathrm{nM}$ concentration. The sample was scanned in a grid pattern with $20 \mu \mathrm{m}$ step size, taking a $1 \mathrm{~s}$ acquisition at each point. The Raman peak intensity at each point was then integrated to create the false-color Raman map that is overlaid on the brightfield image. The FR-positive cell lines (HeLa and SK-BR-3) show high Raman intensity coming from the cluster of cells, whereas the FR-negative cell line (MDA-MB-468) shows little to no Raman signal. Scale bars are $100 \times 50 \mu \mathrm{m}$. 


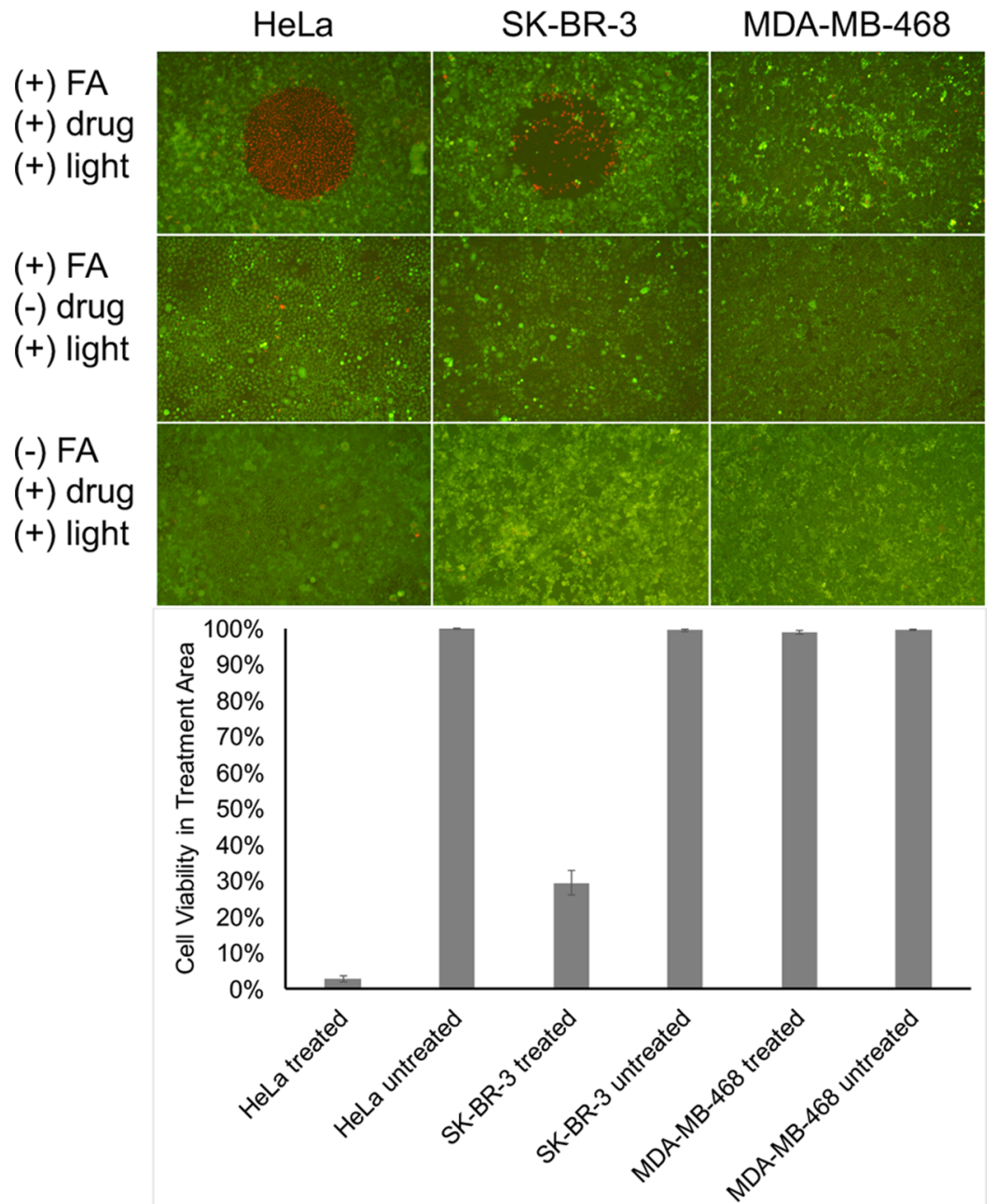

Figure 3. Cell viability staining after PDT with the theranostic construct, a targeted theranostic construct without drug control and an untargeted theranostic construct with drug control. All cells were incubated with the nanoparticle samples at $0.1 \mathrm{nM}$ concentration for $4 \mathrm{~h}$. The scale of each image is $\sim 1.86 \times 1.24 \mathrm{~mm}^{2}$. The number of live and dead cells in the irradiated area, compared with nonirradiated cells, was used to create the histogram displayed to the right of the cell images. Error bars are one standard deviation $(n=4)$.

before live/dead staining. The results of the PDT can be seen in Figure 3. The complete theranostic construct (row 1) showed almost complete cell death for HeLa, a high percentage of cell death for SK-BR-3, and little to no cell death for MDAMD-468. The amount of cell death in the SK-BR-3 sample is likely underestimated, as many of the cells in the irradiated area became detached, as observed in Figure 3. The SK-BR-3 cells may be more sensitive to environmental stresses than the HeLa cells, causing them to detach after PDT. Otherwise, these results are what was expected based on the FR expression of the cell lines.

To verify that the cell death was due to PDT rather than photothermal or other light-induced effects, the targeted nanoparticle construct without PpIX was used as a control (row 2). As shown, there is no cell death after irradiation in the absence of PpIX. Likewise, without FA for targeting (row 3), there are not enough particles uptaken by cells during the incubation period to cause any PDT effects after irradiation. The biocompatibility of the theranostic construct was evaluated using a resazurin-based cell viability assay after the $4 \mathrm{~h}$ incubation period (Figure S3). There is a slight decrease in the cell viability measured after particle incubation; however, none of the observed differences were found to be statistically significant.

\section{EXPERIMENTAL SECTION}

3.1. Materials. All chemicals were purchased from SigmaAldrich (St. Louis, MO) at the highest purity grade available unless otherwise specified. Ammonium hydroxide $\left(\mathrm{NH}_{4} \mathrm{OH}\right.$; $50 \% \mathrm{v} / \mathrm{v}$ ) and ethanol (EtOH; 200 proof) were obtained from VWR (Radnor, PA). FA-PEG-NHS was acquired from Nanocs Inc. (New York, NY). All cell culture reagents, fluorescein diacetate (FDA), propidium iodide (PI), and PBS were purchased from Invitrogen (Carlsbad, CA). Ultrapure deionized (DI) water $(>18 \mathrm{M} \Omega \cdot \mathrm{cm})$ was used in all preparations.

3.2. Instrumentation. TEM was performed on a FEI Tecnai $G^{2}$ Twin (Hillsboro, OR). Particle size distribution and concentration were measured using NTA with a NanoSight NS500 instrument (Malvern, Worcestershire, UK). Raman spectra were acquired using a Renishaw inVia Raman microscope (Gloucestershire, UK), equipped with a $633 \mathrm{~nm}$ $\mathrm{He}-\mathrm{Ne}$ laser. UV/vis spectra and fluorescence intensity were recorded on a FLUOstar Omega plate reader (BMG Labtech $\mathrm{GmbH}$, Germany). Fluorescent emission spectra were recorded 
on an Edinburgh Photonics FLS920 fluorescence spectrometer (Livingston, UK). Folic acid absorption spectra were acquired with a Shimadzu UV-3600 spectrophotometer (Columbia, $\mathrm{MD})$. Photodynamic therapy treatment and cell viability imaging were performed on an inverted microscope with a mercury arc lamp and appropriate filter cubes. Cell images were acquired with a Canon EOS Rebel XTi (Tokyo, Japan) mounted on the front port of the microscope.

3.3. SERS-Labeled Nanoparticle Synthesis. Gold nanostars were synthesized as previously reported. In brief, $10 \mu \mathrm{L}$ of $1 \mathrm{~N} \mathrm{HCl}$ was added to $10 \mathrm{~mL}$ of $0.25 \mathrm{mM} \mathrm{HAuCl}_{4}$ under vigorous stirring. Then, $100 \mu \mathrm{L}$ of $12 \mathrm{~nm}$ gold seed, $50 \mu \mathrm{L}$ of 2 $\mathrm{mM} \mathrm{AgNO}$, and $50 \mu \mathrm{L}$ of $0.1 \mathrm{M} \mathrm{AA}$ were added in rapid succession. The color of the solution changes from orange-red to blue-gray within seconds. A final concentration of $20 \mu \mathrm{M}$ pMBA and $0.02 \%$ Tween 20 was added to the as-prepared particles and allowed to gently stir for $24 \mathrm{~h}$. The solution was again brought to a rapid stir before adding $50 \mu \mathrm{L}$ of $0.1 \mathrm{M}$ $\mathrm{AgNO}_{3}, 50 \mu \mathrm{L}$ of $0.1 \mathrm{M} \mathrm{AA}$, and $10 \mu \mathrm{L}$ of $\mathrm{NH}_{4} \mathrm{OH}$ in sequence. Once thoroughly mixed, gentle stirring was continued overnight. The solution gradually changed to a highly scattering, deep red color. A $5 \mu \mathrm{M}$ final concentration of thiol-PEG 5k was added and allowed to react for $1 \mathrm{~h}$. The particles were washed by centrifugation/resuspension ( $3 \mathrm{k} \mathrm{rcf}, 15 \mathrm{~min}$ ) in water three times and finally redispersed into $1 \mathrm{~mL}$ of water.

3.4. Silica Coating and PpIX Embedding. The SERSlabeled nanoparticles were coated with silica using a modified Stöber method. ${ }^{1} 1 \mathrm{~mL}$ of concentrated nanoparticles was added to $8 \mathrm{~mL}$ of EtOH, and $1 \mathrm{~mL}$ of $\mathrm{DI}$ in a $15 \mathrm{~mL}$ centrifuge tube and was mixed. A final concentration of $1 \mu \mathrm{M}$ protoporphyrin IX (PpIX), $30 \mu \mathrm{L}$ of $10 \%$ TEOS, and $200 \mu \mathrm{L}$ of $\mathrm{NH}_{4} \mathrm{OH}$ was then added, mixed, and kept undisturbed overnight to form PpIX-embedded silica shells on the particles. The silica-coated particles were washed in ethanol three times ( $3 \mathrm{k} \mathrm{rcf,} 15 \mathrm{~min}$ ) and redispersed into $8 \mathrm{~mL}$ of $\mathrm{EtOH}$ and $2 \mathrm{~mL}$ of DI.

3.5. Folic Acid Functionalization. The particles were first modified with APTES to provide free amine groups on the particle surface. A $1 \mu \mathrm{L}$ aliquot of APTES was added to the EtOH/DI particle suspension and allowed to react for $6 \mathrm{~h}$. The APTES-modified particles were washed four times in EtOH and resuspended in $1 \mathrm{~mL}$ of PBS. To this solution, $2 \mathrm{mg}$ of FA-PEG-NHS was added and mixed until dissolved. The reaction was allowed to proceed overnight at room temperature. The FA-functionalized particles were washed three times (3k rcf, $10 \mathrm{~min}$ ) in PBS with $0.02 \%$ Tween 20, with final resuspension in $1 \mathrm{~mL}$ of PBS (particle concentration $\approx 1 \mathrm{nM}$ ).

3.6. Cell Culture and Nanoparticle Incubation. HeLa, SK-BR-3, and MDA-MB-468 cells were obtained from ATCC (Manassas, VA). All three cell lines were cultured in high glucose Dulbecco's modified Eagle medium (Gibco, 11995065 ), supplemented with $10 \%$ fetal bovine serum, and grown at $37{ }^{\circ} \mathrm{C}$ in a humidified atmosphere containing $5 \%$ $\mathrm{CO}_{2}$. For PDT experiments, cells were seeded into six-well plates and grown to $\sim 90 \%$ confluency before use. For Raman mapping experiments, cells were seeded into glass-bottomed 35 $\mathrm{mm}$ dishes and grown to $\sim 50 \%$ confluency before use.

Immediately before particle incubation, the old medium was aspirated and replaced with a fresh medium. To each well, 100 $\mu \mathrm{L}$ of $1 \mathrm{nM}$ nanoparticle solution in PBS was added, and the cells were returned to the incubator for $4 \mathrm{~h}$. The cells were then washed three times with PBS to remove any unbound particles, and the fresh medium was replenished.
Toxicity of the theranostic nanoparticles was measured with a resazurin-based metabolic assay (TOX8, Sigma). Cells were incubated with particles for $4 \mathrm{~h}$, washed in PBS, and then had fresh medium added. The next day, $10 \%$ volume of resazurin solution was added to each well and allowed to incubate for $2 \mathrm{~h}$. The fluorescence intensity was then measured per the manufacturer's protocol.

3.7. Photodynamic Therapy. The cells were irradiated for $15 \mathrm{~s}$ on a microscope using a filtered $(640 / 30 \mathrm{~nm})$ mercury lamp through a $40 \times$ objective, with a power of $11.5 \mathrm{~mW}$ at the sample. After treatment, the cells were placed back in the incubator for $4 \mathrm{~h}$ before staining. Live/dead staining was performed using FDA and PI in PBS at 50 and $1 \mu \mathrm{g} / \mathrm{mL}$, respectively. The live/dead cells in the treated area were counted to produce the cell viability histogram.

3.8. Raman Mapping. After nanoparticle incubation, the cells were fixed in cold methanol for $15 \mathrm{~min}$, rinsed with water, and allowed to dry. A Renishaw inVia Raman microscope equipped with a $633 \mathrm{~nm} \mathrm{He-Ne} \mathrm{laser,} \mathrm{running} \mathrm{WiRE} 2.0$ software, was used to acquire the Raman spectra. Cells were located under brightfield transillumination with a $10 \times$ objective. The motorized stage was then set to scan the sample in a grid pattern while acquiring a spectrum at each point. The grating was set to $1100 \mathrm{~cm}^{-1}$, and the exposure time was $1 \mathrm{~s}$. The falsecolor Raman maps were created by integrating the signal to baseline of the $1076 \mathrm{~cm}^{-1}$ Raman peak of pMBA from 1050 to $1100 \mathrm{~cm}^{-1}$ in the WiRE 2.0 software.

\section{CONCLUSIONS}

In summary, we report the synthesis of a FR-targeted theranostic nanocomposite for SERS-based detection and PDT. The selective detection of FR-positive cells was demonstrated using Raman imaging, showing a high SERS signal from the FR-positive cells and little to no signal from the FR-negative cells. The selective therapeutic effect was demonstrated by performing an in vitro PDT study. Again, only the FR-positive cells were affected by the treatment. The HeLa cells in the irradiated area were almost completely dead, and the SK-BR-3 cells showed a high percentage of cell death, even though many of the cells detached from the treatment area. The FR-negative MDA-MD-468 cells showed no cell death in the irradiated area. These data suggest that the silicacoated, silver-embedded gold nanostars are a promising platform for the development of future theranostic agents. Use of other small-molecule Raman dyes can provide the particles with unique SERS spectra for the application in multiplex detection when combined with other specific targeting agents, such as antibodies.

\section{ASSOCIATED CONTENT}

\section{S Supporting Information}

The Supporting Information is available free of charge on the ACS Publications website at DOI: 10.1021/acsomega.6b00176.

Calibration curves for the quantitation of PpIX and FAPEG, Raman mapping of the three different cell lines, and resazurin-based cell viability assay of the three cell lines (PDF)

\section{AUTHOR INFORMATION}

\section{Corresponding Author}

*E-mail: tuan.vodinh@duke.edu. Phone: (919) 660-8520. Fax: (919) 613-9145 (T.V.-D.). 


\section{Present Address}

"Center for Devices and Radiological Health, U.S. Food and Drug Administration, 10903 New Hampshire Ave, Building 62, Room G205C, Silver Spring, MD 20993 (A.M.F.).

\section{Author Contributions}

${ }^{\perp}$ A.M.F. and B.M.C. contributed equally to this work.

\section{Notes}

The authors declare no competing financial interest.

\section{ACKNOWLEDGMENTS}

This work was sponsored by the Defense Advanced Research Projects Agency (HR0011-13-2-0003) and the Duke University Exploratory Research Funds. The content of this article does not necessarily reflect the position or the policy of the U.S. Government, and no official endorsement should be inferred.

\section{REFERENCES}

(1) Xie, J.; Lee, S.; Chen, X. Nanoparticle-Based Theranostic Agents. Adv. Drug Delivery Rev. 2010, 62, 1064-1079.

(2) Kelkar, S. S.; Reineke, T. M. Theranostics: Combining Imaging and Therapy. Bioconjugate Chem. 2011, 22, 1879-1903.

(3) Ryu, J. H.; Lee, S.; Son, S.; Kim, S. H.; Leary, J. F.; Choi, K.; Kwon, I. C. Theranostic Nanoparticles for Future Personalized Medicine. J. Controlled Release 2014, 190, 477-484.

(4) Muthu, M. S.; Leong, D. T.; Mei, L.; Feng, S.-S. Nanotheranostics-Application and Further Development of Nanomedicine Strategies for Advanced Theranostics. Theranostics 2014, 4, 660-677.

(5) Peng, Y.; Xiong, B.; Peng, L.; Li, H.; He, Y.; Yeung, E. S. Recent Advances in Optical Imaging with Anisotropic Plasmonic Nanoparticles. Anal. Chem. 2015, 87, 200-215.

(6) Vo-Dinh, T.; Fales, A. M.; Griffin, G. D.; Khoury, C. G.; Liu, Y.; Ngo, H.; Norton, S. J.; Register, J. K.; Wang, H.-N.; Yuan, H. Plasmonic Nanoprobes: From Chemical Sensing to Medical Diagnostics and Therapy. Nanoscale 2013, 5, 10127-10140.

(7) Vo-Dinh, T.; Liu, Y.; Fales, A. M.; Ngo, H.; Wang, H.-N.; Register, J. K.; Yuan, H.; Norton, S. J.; Griffin, G. D. SERS Nanosensors and Nanoreporters: Golden Opportunities in Biomedical Applications. Wiley Interdiscip. Rev.: Nanomed. Nanobiotechnol. 2015, 7, $17-33$.

(8) Zhang, G.; Li, J.; Shen, A.; Hu, J. Synthesis of Size-Tunable Chitosan Encapsulated Gold-Silver Nanoflowers and Their Application in SERS Imaging of Living Cells. Phys. Chem. Chem. Phys. 2015, 17, 21261-21267.

(9) Farhadi, A.; Roxin, Á.; Wilson, B. C.; Zheng, G. Nano-Enabled SERS Reporting Photosensitizers. Theranostics 2015, 5, 469.

(10) Fales, A. M.; Yuan, H.; Vo-Dinh, T. Development of Hybrid Silver-Coated Gold Nanostars for Nonaggregated Surface-Enhanced Raman Scattering. J. Phys. Chem. C 2014, 118, 3708-3715.

(11) Pallaoro, A.; Braun, G. B.; Moskovits, M. Biotags Based on Surface-Enhanced Raman Can Be as Bright as Fluorescence Tags. Nano Lett. 2015, 15, 6745-6750.

(12) Wang, Y.; Yan, B.; Chen, L. SERS Tags: Novel Optical Nanoprobes for Bioanalysis. Chem. Rev. 2013, 113, 1391-1428.

(13) Dolmans, D. E. J. G. J.; Fukumura, D.; Jain, R. K. Photodynamic Therapy for Cancer. Nat. Rev. Cancer 2003, 3, 380-387.

(14) Castano, A. P.; Demidova, T. N.; Hamblin, M. R. Mechanisms in Photodynamic Therapy: Part One-Photosensitizers, Photochemistry and Cellular Localization. Photodiagn. Photodyn. Ther. 2004, 1, 279-293.

(15) Rossi, L. M.; Silva, P. R.; Vono, L. L. R.; Fernandes, A. U.; Tada, D. B.; Baptista, M. S. Protoporphyrin IX Nanoparticle Carrier: Preparation, Optical Properties, and Singlet Oxygen Generation. Langmuir 2008, 24, 12534-12538.

(16) Lee, S. J.; Koo, H.; Lee, D.-E.; Min, S.; Lee, S.; Chen, X.; Choi, Y.; Leary, J. F.; Park, K.; Jeong, S. Y.; Kwon, I. C.; Kim, K.; Choi, K. Tumor-Homing Photosensitizer-Conjugated Glycol Chitosan Nano- particles for Synchronous Photodynamic Imaging and Therapy Based on Cellular On/Off System. Biomaterials 2011, 32, 4021-4029.

(17) Bechet, D.; Couleaud, P.; Frochot, C.; Viriot, M.-L.; Guillemin, F.; Barberi-Heyob, M. Nanoparticles as Vehicles for Delivery of Photodynamic Therapy Agents. Trends Biotechnol. 2008, 26, 612-621.

(18) Kularatne, S. A.; Low, P. S. In Cancer Nanotechnology: Methods and Protocols; Grobmyer, S. R., Moudgil, B. M., Eds.; Humana Press: Totowa, NJ, 2010; pp 249-265.

(19) Meier, R.; Henning, T. D.; Boddington, S.; Tavri, S.; Arora, S.; Piontek, G.; Rudelius, M.; Corot, C.; Daldrup-Link, H. E. Breast Cancers: MR Imaging of Folate-Receptor Expression with the FolateSpecific Nanoparticle P1133. Radiology 2010, 255, 527-535.

(20) Jhaveri, M. S.; Rait, A. S.; Chung, K. N.; Trepel, J. B.; Chang, E. $\mathrm{H}$. Antisense Oligonucleotides Targeted to the Human Alpha Folate Receptor Inhibit Breast Cancer Cell Growth and Sensitize the Cells to Doxorubicin Treatment. Mol. Cancer Ther. 2004, 3, 1505-1512.

(21) Chen, H.; Ahn, R; Van den Bossche, J.; Thompson, D. H.; O'Halloran, T. V. Folate-Mediated Intracellular Drug Delivery Increases the Anticancer Efficacy of Nanoparticulate Formulation of Arsenic Trioxide. Mol. Cancer Ther. 2009, 8, 1955-1963.

(22) Fales, A. M.; Yuan, H.; Vo-Dinh, T. Silica-Coated Gold Nanostars for Combined Surface-Enhanced Raman Scattering (SERS) Detection and Singlet-Oxygen Generation: A Potential Nanoplatform for Theranostics. Langmuir 2011, 27, 12186-12190.

(23) Fales, A. M.; Vo-Dinh, T. Silver Embedded Nanostars for SERS with Internal Reference (SENSIR). J. Mater. Chem. C 2015, 3, 73197324.

(24) Fales, A. M.; Yuan, H.; Vo-Dinh, T. Cell-Penetrating Peptide Enhanced Intracellular Raman Imaging and Photodynamic Therapy. Mol. Pharmaceutics 2013, 10, 2291-2298.

(25) Liu, Y.; Yuan, H.; Fales, A. M.; Vo-Dinh, T. pH-Sensing Nanostar Probe Using Surface-Enhanced Raman Scattering (SERS): Theoretical and Experimental Studies. J. Raman Spectrosc. 2013, 44, 980-986.

(26) Fernández-López, C.; Mateo-Mateo, C.; Álvarez-Puebla, R. A.; Pérez-Juste, J.; Pastoriza-Santos, I.; Liz-Marzán, L. M. Highly Controlled Silica Coating of PEG-Capped Metal Nanoparticles and Preparation of SERS-Encoded Particles. Langmuir 2009, 25, 1389413899. 